\title{
FPMRS challenges on behalf of the Collaborative Research in Pelvic Surgery Consortium (CoRPS): managing complicated cases series 4: is taking out all of a mesh sling too extreme?
}

\author{
Emily B. Rosenfeld ${ }^{1} \cdot$ Ladin A. Yurteri-Kaplan ${ }^{2} \cdot$ Chris Maher $^{3} \cdot$ Tony Bazi $^{4} \cdot$ Kamil Svabik $^{5} \cdot$ Sara Houlihan $^{6}$. \\ Cara L. Grimes ${ }^{1}$
}

Received: 31 August 2019 / Accepted: 28 October 2019/Published online: 2 December 2019

(C) The International Urogynecological Association 2019

\section{Case}

A 46-year-old P2 presented with mesh exposure after a midurethral sling (MUS) procedure. She had a history of prolapse and mixed urinary incontinence and underwent a robotic-assisted total laparoscopic hysterectomy, bilateral salpingectomy, uterosacral colposuspension and MUS (Solyx Single-Incision Sling, Boston Scientific, USA). Six months after surgery, per patient, she was found to have vaginal granulation tissue that was excised in the operating room. Three months after that, she presented to her initial surgeon with dyspareunia and hispareunia. She tried a 12-week course of vaginal estrogen without resolution. Upon presentation, she complained of persistent mesh exposure, palpable to her and her husband, causing dyspareunia. On examination, no mesh could be visualized or felt, but palpation along a portion of the left sling arm revealed tenderness and

Ladin A. Yurteri-Kaplan

ly2401@cumc.columbia.edu

1 Department of Obstetrics and Gynecology, New York Medical College, Valhalla, NY, USA

2 Department of Obstetrics and Gynecology, Columbia University Medical Center, 622 West 168th Street, New York, NY 10032, USA

3 Wesley and Royal Brisbane and Women's Urogynaecology, University of QLD, Brisbane, Queensland, Australia

4 Department of Obstetrics and Gynecology, American University of Beirut, Beirut, Lebanon

5 First Faculty of Medicine, Charles University and General University Prague, Prague, Czech Republic

6 Department of Obstetrics and Gynecology, Royal Columbian Hospital, University of British Columbia, Vancouver, Alberta, Canada thin overlying epithelium. No recurrent prolapse was noted. The patient strongly desires complete removal of the mesh, stating her reason for removal was "it is mesh."

How would you proceed?

\section{Expert urogynecologist recommendations}

\section{Recommendations from an expert, Dr. C. Maher (Urogynecology, Queensland, Australia)}

Prior to her visit I would seek the operating notes from her two most recent interventions and histology and microbiology assessment from the removal of "granulation tissue" surgery. Per my normal practice, she would have completed the validated Australian Pelvic Floor Questionnaire to document the status of her bladder, bowel, prolapse and sexual function. I would also repeat the vaginal examination augmented with a 3D ultrasound assessment of the tape allowing the patient to visualize the tape in relationship (distance and symmetry) to the urethra and to exclude other pathology. Finally, I would invite the patient to articulate her concerns regarding the mesh and utilize a variety of evidence-based literature and patient testimonials to fully complete her understanding of complications regarding mini-sling tapes and vaginal mesh in general.

The patient should be reassured that I would seek to work with her to obtain her best perceived outcome after being fully informed of the risk and benefits of all the treatment options. The clinical findings demonstrated a tender left arm of the mini-sling tape that sits under thin vaginal mucosa, and this is likely to be the cause of the dyspareunia. The only plausible explanation for the hispareunia is a small vaginal mesh exposure that the examination has not identified. 
The options for treatment to be discussed with the patient include:

(1) Further 3 months of conservative treatment including vaginal estrogen therapy and dedicated pelvic floor physiotherapy aimed at maximizing the possibility of symptom resolution without intervention.

(2) Partial excision of the tender left arm of the mini-sling. This option focuses on the limited removal of the tape to remove the source of the painful tape. It minimizes the surgical intervention and leaves the right side of the tape present, which may serve to decrease the risk of stress urinary incontinence (SUI) returning.

(3) Total removal of the mini-sling tape and the anchors. The patient needs a full discussion of the risk and benefits of this option, which include:

(a) A more significant intervention than the partial removal with longer operating time, increased risk of bleeding requiring transfusion $(1 \%)$ and damage to the urethra or bladder $(1 \%)[1,2]$.

(b) Risk of incomplete removal especially with retention of one or both tape anchors $(10 \%)$.

(c) Persisting dyspareunia $(40 \%)[3,4]$.

(d) Worsening of SUI (40\%) [5].

The patient should also understand if following the partial or complete removal of the mini-sling the SUI significantly worsens, a variety of surgical options remain available that could be considered 3-6 months post removal.

While discussing all options with the patient and her partner, I would encourage option (1) for a further 12-week trial of conservative treatment. I would reassure her that if the symptoms persist, we could accelerate the timing of the surgical intervention. Eventually, I expect that this patient, after consultation with her partner, friend and on-line discussions, will elect for treatment option (3) but will do so after being fully informed of the risk/benefit profile of the total removal of the mini-sling.

\section{Recommendations from an expert, Dr. T. Bazi (Urogynecology, Beirut, Lebanon)}

First, it is helpful to get the operative report and findings of the intervention done 6 months after the initial surgery for vaginal granulation tissue. It is important to get details about dyspareunia and hispareunia location and assess if the same pain can be reproduced by palpation of the tender left portion of the arm. Regardless of one's interpretation of the patientstated reason behind her request for sling removal ("it is all mesh"), one must take all symptoms related to MUS placement seriously. Pain is not necessarily exclusively present along known nerve sensory areas. Aberrant nerve branches as well as referred pain can lead to unusual pain pattern locations after MUS. In this specific case, however, the tender area was clearly located in the left portion where the epithelium is thin, though the mesh could not be palpated. I think that the patient's wish should be honored, and an attempt at removal of one or both vaginal portions of the sling should be undertaken. Preoperative counseling would target two issues. The first is that removal of one or both arms, while likely resulting in symptom improvement, is not guaranteed to totally eliminate dyspareunia and sexual dissatisfaction. The second is the significant risk of recurrence of urinary stress incontinence following excision of one or both arms of a MUS. During the surgical excision intervention, I would not place another sling, whether synthetic or autologous.

\section{Recommendations from an expert, Dr. K. Svabik (Urogynecology, Prague, Czech Republic)}

I would offer the patient a sling removal. This is not an asymptomatic patient. She (and her husband) have dyspareunia and hispareunia. On examination, the sling is palpable with thin epithelium and confirms tenderness, which implies the sling is close to the epithelium and is causing the problems. Also, there is a history of granulation tissue. If the location of the granulation tissue is the same location as the localized tenderness found on examination, it would further support the wrong (superficial) layer of sling insertion confirming the sling's close proximity to the vaginal tissue. I would perform an ultrasound prior to removal to confirm the location of the sling. Because this was a single-incision sling, the removal of the sling should not be a difficult procedure and is very likely to solve the problem without high risk of complications. In my opinion, I would not perform a prolapse surgery and sling at the same time for a patient with prolapse and mixed urinary incontinence. Instead, I would first address the prolapse and later at a second surgery address the incontinence.

\section{Recommendations from an expert, Dr. S. Houlihan (Urogynecology, Alberta, Canada)}

Mesh exposure and dyspareunia following MUS insertion are recognized complications. Published rates of exposure are 1$2 \%$ [6] whereas rates of pain and dyspareunia can be as high as $30 \%$ [7]. Risk factors for MUS exposure include younger age, concomitant apical and anterior prolapse repair and diabetes while pre-existing pain syndromes (including fibromyalgia), higher somatization and poorer general health put patients at risk of postoperative dyspareunia [8, 9]. Among women who undergo MUS insertion, the rate of removal at 9 years is estimated at $3.3 \%$ [10].

A complete history should be performed including understanding her motivations for mesh removal as well as her expectations as to what full removal will achieve. A comprehensive urogynecologic examination should be conducted 
(including evaluation for pelvic floor tension myalgia), detailed neurologic review and midstream urine microscopy and culture. Cystoscopy is imperative. Urodynamics may be indicated depending on symptoms, particularly if she had mixed incontinence prior to her index surgery. If she has recurrent incontinence a dynamic ultrasound may be useful.

Review of the operative reports will provide information on the colposuspension (suture type) and if there are issues with the placement of the MUS. The description of the "vaginal granulation tissue excision" operation will be equally useful in indicating whether the mesh was incised/excised or even visible at the interval surgery. If a specimen was sent to pathology, review of the report or slides should be done to see if polypropylene fibers were present.

I would then offer the patient the options of conservative management with continued vaginal estrogen, pelvic floor physiotherapy (PFPT) and/or trigger point injection versus operative management with mesh excision. She has tried vaginal estrogen without success but adding PFPT may be beneficial if the dyspareunia is caused by tethering of muscle by the sling contributing to pelvic floor muscle hypertonia (or pain unrelated to the mesh).

Surgical excision could be either partial or complete mesh excision. Preoperative counseling is exceedingly important to discuss realistic treatment expectations. Urinary symptoms would help guide the extent of mesh excision. If she is continent, I would urge her to consider a partial excision as there is limited evidence that complete removal provides better pain relief. However, the more mesh that is removed, the higher the rate of recurrent SUI (36-47\%) [1]. If she was adamant about complete excision or had recurrent SUI, I could remove the entire mesh and conical carriers (deployed in the obturator internus muscle) transvaginally provided that the patient understands the high risk of recurrent SUI as well as the risk of new chronic pelvic pain related to repeat surgery. Whether undertaking partial or complete excision, I would emphasize that mesh excision can be complicated technically and fraught with additional complications due to urethral and bladder/ureter injury.

The patient does need to make an informed decision up front as with a partial excision the mesh arms can track laterally to the pubic ramus and may be difficult to retrieve in a second surgery. This is especially important if the patient does have ongoing pain from partial excision. Even with appropriate preoperative counseling, the patient may continue to blame residual mesh if her mindset was that "it is the mesh" causing her symptoms.

Finally, I would strongly encourage both pre- and postoperative PFPT if the patient does elect to undergo surgical excision.

\section{How the case was managed}

We offered her a partial excision of the suspected mesh exposure and approximation of the epithelium surrounding the mesh, i.e., a partial mesh removal. She highly desired complete mesh removal and went to an outside provider who performed a robotic assisted-laparoscopic sacrocolpopexy using autologous fascia from her left leg, urethrolysis and complete removal of her mesh sling. She has since returned to our office for postoperative care (as this surgery was performed 3000 miles away). Her postoperative course was complicated by gross hematuria, prolonged pelvic pain and severe mixed incontinence. Her postoperative workup given the stated symptoms included a negative CT urogram and cystoscopy for bladder injury or mesh remnants in the bladder urothelium. Repeat urodynamics confirmed severe stress incontinence and detrusor overactivity. She was offered a second mesh MUS versus Burch colposuspension versus fascial sling, and she has elected to undergo a fascial sling.

\section{Literature review}

SUI affects $15.7 \%$ of women [11]. In 2010, it is estimated that 250,000 MUS procedures were performed in the USA [12, 13]. MUS are widely accepted as the standard of care for treating SUI with success rates ranging from 63 to $97 \%$ [14]. Synthetic mesh was approved by the Food and Drug Administration for MUS for SUI in 1998, and the use has increased over the past 2 decades $[15,16]$. There are over 100 randomized controlled trials with over 10-year followup to demonstrate the safety and efficacy of MUS. Furthermore, MUS is supported by society position statements from several medical societies including AUGS, SUFU, ACOG, AUA, IUGA, SGS and RANZCOG [17-21]. Some of the known complications of slings can happen with any incontinence surgery including urinary retention, pain and dyspareunia, while some are specific to synthetic MUS including vaginal mesh exposure and erosion [22].

Vaginal mesh exposure is defined by IUGA/ICS as "a condition of displaying, revealing, exhibiting or making accessible" and has been reported between 0 and $8.5 \%$ for MUS [23-29]. Studies have shown mesh exposure is associated with trans-obturator tape, older age, diabetes, tobacco use, concurrent total hysterectomy, low body mass index, vaginal incision $>2 \mathrm{~cm}$, previous vaginal surgery for POP or incontinence or vaginal incision for postoperative complications [27, 28].

In women with asymptomatic mesh exposure, they can be expectantly managed if a monofilament mesh was used [22]. In the case of a symptomatic small mesh exposure $(<0.5 \mathrm{~cm})$, the first line of treatment is vaginal estrogen for 6-12 weeks [22]. In a study of 117 women with mesh exposure, vaginal estrogen successfully treated $40 \%$. If vaginal estrogen fails, some experts recommend leaving the mesh in place and mobilizing the epithelium surrounding the mesh to approximate the surrounding tissue and treat the exposure [22]. If the above fails, or in the instance of large $(>2 \mathrm{~cm})$ or non-flat mesh, the 
exposed mesh can be removed. In cases of microporous or multifilament mesh, it is recommended to remove the whole mesh because of risk of infection [30].

Varied approaches to treatment of mesh exposure are described in the literature. Abbott et al. conducted a retrospective multicenter study of 347 women with mesh complications and found that $49 \%$ were initially managed surgically. The most common first-line surgical treatment was trimming of mesh/ partial excision $(51 \%)$ followed by complete mesh excision $(27 \%)$ and release of mesh arms (18\%) [30]. A study of $>$ 60,000 retropubic slings in the UK found that $2.2 \%$ underwent surgery for mesh removal; the majority $(70 \%)$ were partial removals [1]. In a small retrospective study comparing complete versus partial mesh removal for mesh exposure, Jambursaria et al. found significant recurrent postoperative SUI in $52 \%$ of patients with complete mesh removal compared with 25\% recurrent SUI in the partial mesh removal group. Reoperation for recurrent SUI was higher with complete mesh removal (24\%) compared with partial mesh removal (6\%) [31].

Unfortunately, complete mesh excision increases adverse events including recurrent SUI, de novo overactive bladder and urgency urinary incontinence, new pain and surgical complications. It is likely that our patient has had a more complicated postoperative course possibly because of the complete mesh removal including recurrent severe incontinence and need for repeat incontinence treatment. It is likely that if she had undergone a partial mesh excision, she would not have had as severe recurrent stress urinary incontinence.

Experts for this case series were contacted and asked to voluntarily join. The only requirement to participate was to routinely practice urogynecology. Among our experts, in this case series most agree that reviewing prior operative and pathology reports is important before proceeding. All agree that there is likely an exposure that is not initially detected on the initial office examination and that our patient has significant symptoms that are likely due to the location of the left sling arm. Three experts would consider an ultrasound to augment their clinical examination. Most experts recommend considering a longer duration of conservative therapy including continued vaginal estrogen, PFPT and/or trigger point injections. If these treatments fail, most experts considered either a partial (one arm) or total mesh excision. Across experts, there was hesitation to remove all of the mesh because of a perceived higher risk of recurrent stress incontinence with few data to support that complete removal would provide a better cure of her dyspareunia and other symptoms. Most experts recommended counseling about severe adverse events if removing some or all of the mesh - specifically that dyspareunia and sexual dysfunction are not guaranteed to be eliminated after partial or total mesh excision and that there is a significant risk of recurrent stress incontinence with removal, which may increase as more mesh is removed. Some also noted the potential for further complications including urethral and bladder/ureter injury. Given the design of the mini-slings, it is likely easier to remove, and this should be considered in surgical counseling.

Overall, these cautious recommendations regarding the impact of mesh removal on our patient's symptoms echo statements by our national and international organizations. Patients should be fully informed regarding risks including persistent pelvic pain (including dyspareunia) that may not respond to mesh removal, which should be managed by an experienced clinician with appropriate training [22]. The patient should also be aware of having realistic expectations about any intervention and understand that pain resolution after surgery is not uniform [32].

\section{Compliance with ethical standards}

Conflict of interest Grimes: expert witness, Johnson and Johnson.

Svabik: consultant for Boston Scientific and Astellas.

Houlihan: consultant for Boston Scientific and Astellas.

The remaining authors claim no conflict of interest.

Each author was directly involved in the write-up of the case series. Drs. Yurteri-Kaplan and Grimes were involved in editing the case series.

\section{References}

1. Cundiff G, Quinlan D, Rensburg JV, Slack M. Foundation for an evidence-informed algorithm for treating pelvic floor mesh complications: a review. BJOG-Int J Obstet Gy. 2018;125:1026-37. https://doi.org/10.1111/1471-0528.15148.

2. Devakumar H, Chandrasekaran N, Alas A, et al. Resolution of rectal prolapse by vaginal reconstruction. Female Pelvic Med Reconstr Surg. 2017;23:e4-7. https://doi.org/10.1097/spv. 0000000000000354.

3. Dray E, Crosby E, Grable A, et al. A retrospective analysis of surgical outcomes and risk factors for persistent postoperative symptoms following synthetic mid urethral sling revision. J Urol. 2019;202:339-46. https://doi.org/10.1097/ju.0000000000000246.

4. Feiner B, Maher C. Vaginal mesh contraction: definition, clinical presentation, and management. Obstet Gynecol. 2010;115:325-30. https://doi.org/10.1097/aog.0b013e3181cbca4d.

5. Ramart P, Ackerman AL, Cohen SA, et al. The risk of recurrent urinary incontinence requiring surgery after suburethral sling removal for mesh complications. Urology. 2017;106:203-9. https:// doi.org/10.1016/j.urology.2017.01.060.

6. Ford AA, Rogerson L, Cody JD, et al. Mid-urethral sling operations for stress urinary incontinence in women. Cochrane Database Syst Rev. 2017. https://doi.org/10.1002/14651858.cd006375.pub4.

7. Hou JC, Alhalabi F, Lemack GE, Zimmern PE. Outcome of transvaginal mesh and tape removed for pain only. J Urol. 2014;192:856-60. https://doi.org/10.1016/j.juro.2014.04.006.

8. Jonsson Funk M, Siddiqui NY, Pate V, et al. Sling revision/removal for mesh erosion and urinary retention: long-term risk and predictors. Am J Obstet Gynecol. 2013;208:73.e1-7. https://doi.org/10. 1016/j.ajog.2012.10.006.

9. Geller EJ, Babb E, Nackley AG, Zolnoun D. Incidence and risk factors for pelvic pain after mesh implant surgery for the treatment of pelvic floor disorders. J Minim Invas Gyn. 2017;24:67-73. https://doi.org/10.1016/j.jmig.2016.10.001. 
10. Gurol-Urganci I, Geary RS, Mamza JB, et al. Long-term rate of mesh sling removal following midurethral mesh sling insertion among women with stress urinary incontinence. JAMA. 2018;320:1659. https://doi.org/10.1001/jama.2018.14997.

11. Nygaard I, Barber MD, Burgio KL, Kentor K, Meikle S, Schaffer J, et al. Prevalence of symptomatic pelvic floor disorders in US women. Pelvic Floor Disorders Network Jama. 2008;300:1311-6.

12. Erekson EA, Lopes VV, Raker CA, Sung VW. Ambulatory procedures for female pelvic floor disorders in the United States. Am J Obstet Gynecol. 2010;203:497.e1-5. https://doi.org/10.1016/j.ajog. 2010.06.055.

13. Center for Devices and Radiological Health. Considerations about surgical mesh for SUI. In: US Food and Drug Administration, 2019. h t t p s : // w w w.fda.gov/MedicalDevices/ ProductsandMedicalProcedures/ImplantsandProsthetics/ UroGynSurgicalMesh/ucm345219.htm. Accessed 27 Jul 2019.

14. Barber M. Surgical treatment of stress urinary incontinence. In: Bent AE, Cundiff GW, Swift SE, editors. Ostergard's urogynecology and pelvic floor dysfunction. 6th ed. Philadelphia: Lippincott Williams \& Wilkins; 2008. p. 225-62.

15. Jonsson Funk M, Siddiqui NY, Kawasaki A, Wu JM. Long-term outcomes after stress urinary incontinence surgery. Obstet Gynecol. 2012;120:83-90. https://doi.org/10.1097/aog.0b013e318258fbde.

16. Ward K, Hilton P. Tension-free vaginal tape versus colposuspension for primary urodynamic stress incontinence: 5-year follow up. BJOG-Int J Obstet Gy. 2007;115:226-33. https://doi.org/10.1111/ j.1471-0528.2007.01548.x.

17. American College of Obstetricians and Gynecologists and the American Urogynecologic Society. ACOG practice bulletin no. 155: urinary incontinence in women. Obstet Gynecol. 2015;126: 66-81. https://doi.org/10.1097/aog.0000000000001148.

18. Kobashi KC, Albo ME, Dmochowski RR, et al. Surgical treatment of female stress urinary incontinence: AUA/SUFU guideline. J of Urol. 2017;198:875-83. https://doi.org/10.1016/j.juro.2017.06. 061.

19. International Urogynecological Association. Position Statement on Mid-Urethral Slings for Stress Urinary Incontinence, 2018. https:// www.iuga.org/files/48/Position-Statements/6/Position-Statementon-Mid-Urethral-Slings-for-SUI.pdf. Accessed 27 Jul 2019.

20. Royal Australian and New Zealand College of Obstetricians and Gynaecologists (2018) Position statement on midurethral slings. Position statement on midurethral slings. https:/www.ranzcog. edu.au/Statements-Guidelines/Gynaecology/Midurethral-Slings,Position-Statement-(C-Gyn-32). Accessed 27 Jul 2019.

21. Nager C, Tulikangas P, Miller D, et al. Position statement on mesh midurethral slings for stress urinary incontinence. Female Pelvic Med Reconstr Surg. 2014;20:123-5. https://doi.org/10.1097/spv. 0000000000000097

22. American College of Obstetricians and Gynecologists. Management of mesh and graft complications in gynecologic surgery. Committee opinion no. 694. Obstet Gynecol. 2017;129: 102-8. https://doi.org/10.1097/aog.0000000000002022.

23. Haylen BT, Maher CF, Barber MD, et al. An International Urogynecological Association (IUGA)/International Continence Society (ICS) joint report on the terminology for female pelvic organ prolapse (POP). Int Urogynecol J. 2016;27:165-94. https:// doi.org/10.1007/s00192-015-2932-1.

24. Brubaker L, Norton PA, Albo ME, et al. Adverse events over two years after retropubic or transobturator midurethral sling surgery: findings from the trial of midurethral slings (TOMUS) study. Am J Obstet Gynecol. 2011;205:498.e1-6. https://doi.org/10.1016/j.ajog. 2011.07.011.

25. Zullo MA, Plotti F, Calcagno M, et al. One-year follow-up of tension-free vaginal tape (TVT) and trans-obturator suburethral tape from inside to outside (TVT-O) for surgical treatment of female stress urinary incontinence: a prospective randomised trial. Eur Urol. 2007;51:1376-84. https://doi.org/10.1016/j.eururo.2006.10. 066 .

26. Tseng LH, Wang AC, Lin YH, et al. Randomized comparison of the suprapubic arc sling procedure vs tension-free vaginal taping for stress incontinent women. Int Urogynecol J. 2004;16:230-5. https://doi.org/10.1007/s00192-004-1248-3.

27. Kokanali M, Doğanay M, Aksakal O, et al. Risk factors for mesh erosion after vaginal sling procedures for urinary incontinence. Eur J Obstet Gynecol Reprod Biol. 2014;177:146-50. https://doi.org/ 10.1016/j.ejogrb.2014.03.039.

28. El-Khawand D, Wehbe SA, O'Hare PG, et al. Risk factors for vaginal mesh exposure after mesh-augmented anterior repair. Female Pelvic Med Reconstr Surg. 2014;20:305-9. https://doi. org/10.1097/spv.0000000000000095.

29. Richter HE, Albo ME, Zyczynski HM, et al. Retropubic versus transobturator midurethral slings for stress incontinence. $\mathrm{N}$ Engl J Med. 2010;362:2066-76. https://doi.org/10.1056/ NEJMoa0912658.

30. Abbott S, Unger CA, Evans JM, et al. Evaluation and management of complications from synthetic mesh after pelvic reconstructive surgery: a multicenter study. Am J Obstet Gynecol. 2014;210: 163.e1-8. https://doi.org/10.1016/j.ajog.2013.10.012.

31. Jambusaria LH, Heft J, Reynolds WS, et al. Incontinence rates after midurethral sling revision for vaginal exposure or pain. Am J Obstet Gynecol. 2016;215:-764.e1, 5. https://doi.org/10.1016/j.ajog.2016. 07.031.

32. Duckett J, Bodner-Adler B, Rachaneni S, Latthe P. Management of complications arising from the use of mesh for stress urinary incontinence - International Urogynecology Association Research and Development Committee opinion. Int Urogynecol J. 2019. https://doi.org/10.1007/s00192-019-03935-8.

Publisher's note Springer Nature remains neutral with regard to jurisdictional claims in published maps and institutional affiliations. 